\title{
Behavior Toward E-Communication Tools: A New Theoretical Model Based on Evolution Theory
}

\author{
Ned Kock \\ Temple University, USA
}

kock@sbm.temple.edu

\begin{abstract}
This paper presents a new theoretical model to explain behavior toward electronic communication tools based on evolution theory. The model proposes that inherited biological traits acquired by the human species through Darwinian evolution bias an individual's choice of preferred communication toward face-to-face communication. The model also suggests that e-communication media that selectively incorporate elements of actual unencumbered face-to-face interaction (e.g., physical presence, ability to see and hear others, synchronicity) will be perceived as more adequate for communication than other media devoid of those elements, and therefore as demanding less individual cognitive effort to be used, particularly in tasks requiring intense communication.
\end{abstract}

Keywords: Communication Media, Computer-mediated Communication, Evolution Theory, Biological Influences, Electronic Mail.

\section{Introduction}

The use of computer-based electronic communication (ecommunication) tools has its roots in the 1960s with the advent of e-mail systems running on mainframe computers that allowed text messages to be exchanged among users registered in the operating system. These early ecommunication systems gave way to more sophisticated ones with the interconnection of first mainframes, and then desktop computers through networks and the Internet, which have extended the reach of e-mail beyond single organizations. There have also been significant technological innovations in e-communication tools, such as the "group" sense of computer conferencing, the synchronicity and facilitation features of group decision support systems, and the "shared environment" sense provided by videoenhanced media spaces, all made feasible by cheaper technology and increasing bandwidth and connectivity.

\footnotetext{
Material published as part of this proceedings, either on-line or in print, is copyrighted by the author with permission granted to the publisher of Informing Science for this printing. Permission to make digital or paper copy of part or all of these works for personal or classroom use is granted without fee provided that the copies are not made or distributed for profit or commercial advantage AND that copies 1) bear this notice in full and 2) give the full citation on the first page. It is permissible to abstract these works so long as credit is given. To copy in all other cases or to republish or to post on a server or to redistribute to lists requires specific permission from the author.
}

Psychologists and sociologists have studied the use of email and other e-communication tools in many environments and task situations, and attempted to explain interesting phenomena, such as flaming, withdrawal, and increases or decreases in task effectiveness in the context of previous technological and social theories. We believe there is more happening here than can be explained by simple adaptations of previous theories, and believe that a new theoretical look at the phenomena of e-communication tool adoption and use is appropriate.

\section{Theories of e-communication behavior}

Past investigations of e-communication behavior have shown that it is both complex and, notwithstanding much research done in the area, fairly unpredictable (DeSanctis et al., 1993; Postmes et al., 1998). In spite of this, an inspection of the e-communication literature strongly suggests the belief that e-communication behavior depends on a finite number of discrete factors. The search for this "holy grail" has led to the identification of key factors, found in e-communication theories and models developed over the years. Four main factors can be identified from the research literature in the field:

- The communication medium used by two or more individuals engaged in e-communication (Daft and Lengel, 1986; Daft et al., 1987). Examples of e-communication 
media are e-mail, group decision support systems, and videoconferencing systems.

- The task carried out by two or more individuals with support of e-communication (Daft and Lengel, 1986; Daft et al., 1987). Examples of tasks are to prepare a contract, write a business report, and develop a new aircraft hull design.

- The social environment surrounding two or more individuals engaged in e-communication (DeSanctis and Poole, 1994; DeSanctis et al., 1993; Fulk, 1993; Fulk et al., 1990; Markus, 1994). Social environments are complex abstract structures made up of sets of stimuli, which are, by definition, are initially external to each individual and then become internalized as social information processing schemas (note: schemas = mental structures) through communication and learning processes. Examples of such sets of stimuli are memos stating formal and informal organizational norms, peer behavior that reveals cultural background traits, and oral statements by other individuals addressing selfperceptions.

- The information processing schemas held by two or more individuals engaged in e-communication (Lee, 1994; Ngwenyama and Lee, 1997). Information processing schemas (also loosely referred to as "knowledge") are internal to each individual and can be both innate and social. Innate schemas are inborn, e.g., the schemas that guide involuntary behavioral responses in the presence of food, potential mates, and danger. Learned schemas (referred to in this paper as "social" schemas) are constructed over the life of the individual, usually through social interactions, e.g., the schemas that guide context-specific eating behavior in restaurants, flirting behavior in pubs, and danger avoidance behavior in large cities. Information processing schemas influence how stimuli are sensed, interpreted and internalized by individuals. They also provide the basis for decision-making and action taking in reaction to stimuli.

Social environment and social information processing schemas evolve over time and build on each other. That is, past social environments in which an individual has lived or worked may influence the formation of current social information processing schemas. Similarly, information processing schemas developed over time may influence how cues from the social environment are interpreted.
Figure 1 illustrates the relationship among the factors above. In Figure 1, two individuals, John and Mary, undertake a collaborative task using a communication medium. A social environment surrounds each individual. The components of each social environment can be specific to that environment or overlap with those of the social environment surrounding the other individual. Each individual holds information processing schemas, which can be specific to that individual or overlap with information processing schemas held by the other individual.

Empirical research on e-communication has been conducted since the late 1970s, initially addressing asynchronous technologies (i.e., technologies that allow users to interact at different times). The 1980s have seen the emergence of several theories developed largely to explain accumulated empirical findings from the 1970s and 1980s. At the same time, more empirical research began to be produced based on experiments involving synchronous group decision support systems, which also led to the development of other theories. This theoretical body can be grouped into two main types, technological and social theories.

Technological theories of e-communication place particular emphasis on the fit between task and medium as a determinant of communication process and outcomes. That is, the foci of these theories are the communication medium and the task being accomplished through it. Examples of technological theories are media richness theory (Daft and Lengel, 1986; Daft et al., 1987; Lengel and Daft, 1988), the gains and losses model (Alavi, 1994; Nunamaker et al., 1991), and the task/technology fit theory proposed by Zigurs and Buckland (1998).

Among technological theories, perhaps the best known is media richness theory (Daft and Lengel, 1986; Daft et al., 1987; Lengel and Daft, 1988), which has been quite influential among e-communication tools developers and researchers (Jackson and Purcell, 1997; Kock, 1998; Lee, 1994; Markus, 1994), even though it was developed before the advent of most of the e-communication tools in use today. Media richness theory argues that rational individuals predictably favor the use of specific communication media to accomplish certain tasks. Media richness theory classifies different communication media according to a richness scale that features face-to-face $(\mathrm{FtF})$ interaction at the top and printed documents at the bottom, with ecommunication media somewhere in between (Lee, 1994; Markus, 1994). A key hypothesis of media richness theory is that rich media are more appropriate to support "equivo- 


\section{Behavior Toward E-Communication Tools}

cal" communication (which is likely to occur in complex tasks) than lean media, and that aggregate data about rational individual media choices would consistently support this hypothesis.

Social theories of e-communication place emphasis on the role of the social environment and socially constructed information processing schemas in defining behavior toward e-communication technology. Examples of these theories are the social influence model (Fulk et al., 1990), critical mass theory (Markus, 1990), adaptive structuration behavior. Since social influences occur only after birth, shaping the behavior of an individual throughout her lifetime, it follows that innate behavior (which is primarily defined by innate schemas) is not at all affected by social influences. Instincts can no doubt be curbed by social influences, but their source is primarily innate (or genetic). Pure innate behavior is rarely found in society today, due to the multitude and strength of social influences. Yet, innate behavior is never completely suppressed and clearly surfaces depending on the circumstances. For example, individuals deprived from food for several days will react

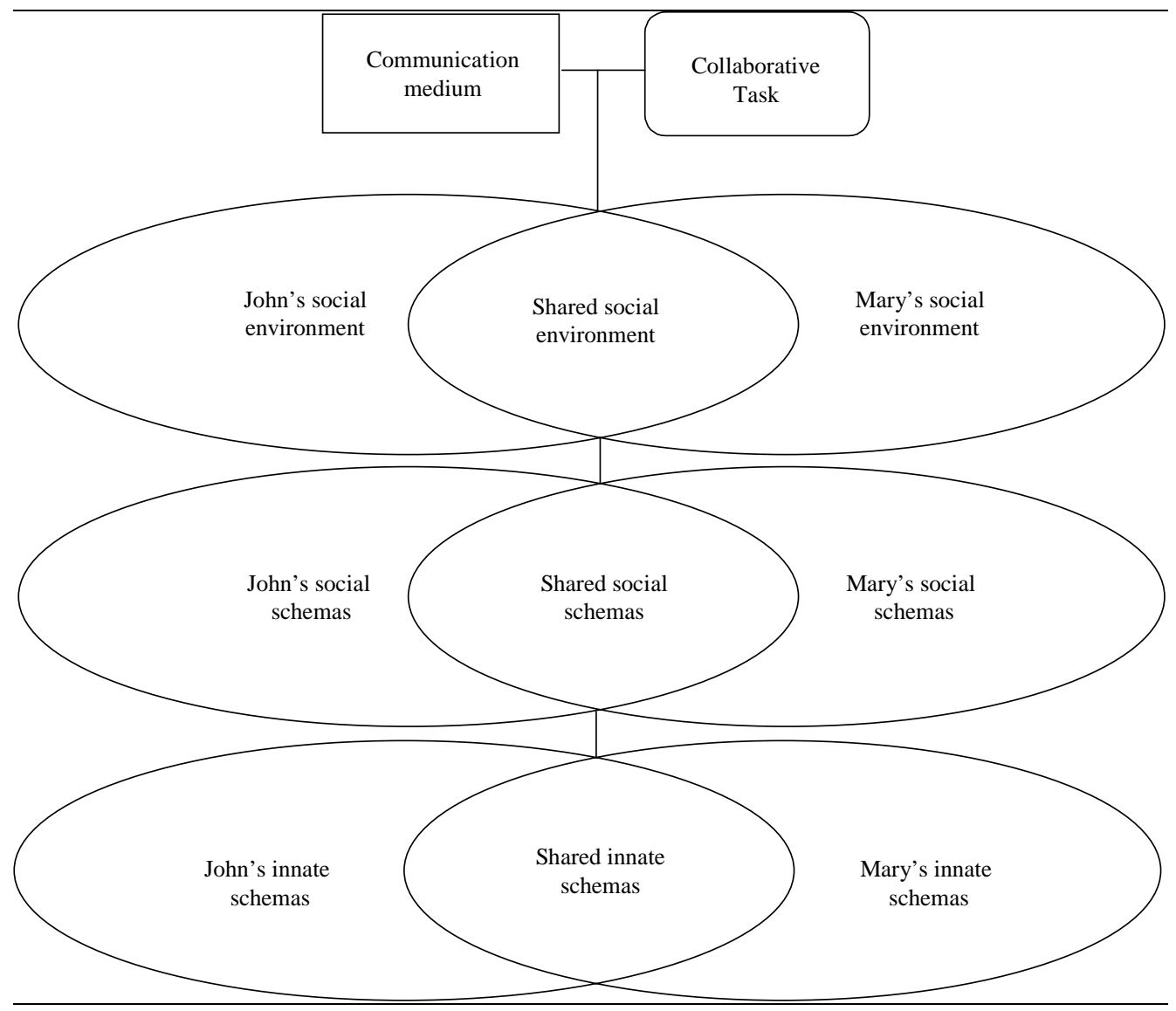

Figure 1: Key factors influencing e-communication behavior

theory (DeSanctis and Poole, 1994; DeSanctis et al., 1993; Poole and DeSanctis, 1990), and the technology metastructuration model (Orlikowski et al., 1995).

Social theories are seen by many as representing a major step in our understanding of e-communication phenomena. However, the emphasis of social theories on social influences has prevented them from contributing to the understanding of innate influences on e-communication to it in very similar and instinctive ways. Their behavior would be more socially determined if they were not so hungry, and would not be similar if their social schemas related to eating were significantly different (e.g., individuals from different national cultures whose eating costumes are entirely different). Innate behavior is a result of biological mechanisms developed by human beings through Darwinian evolution, mechanisms that have been 
largely ignored by both technological and social ecommunication theories.

\section{The forgotten role of biology on e-communication behavior}

The relevance of studying the effect of innate influences on e-communication behavior comes from one important hypothesis: Human beings have been "engineered" by evolution to communicate FtF, and FtF only. The human species evolved through natural selection, a process in which random genetic mutations introduce individual traits that were selected based on their usefulness for survival and mating (Darwin, 1859; Dawkins, 1989). The evolutionary pace set by natural selection is usually very slow (Boaz and Almquist, 1997; Lorenz, 1983), leading to the development of physical, behavioral and cognitive traits over long periods of time (which may span thousand or
As indicated in Figure 2, research evidence points at the use of facial expressions and a simple set of discrete sounds for communication as early as 5 to 2 million years ago, by members of the australopithecine genus such as Australopithecus afarensis and africanus (Boaz and Almquist, 1997). This behavioral trait, also found in modern primates and many other mammals, has been refined over millions of years, leading to the appearance of rudimentary forms of speech, and later complex speech (Isaac, 1993; Laitman, 1993). Only late in the human evolutionary cycle there is evidence of communication through pictorial representations, mostly in the form of cave paintings, which can be seen as early manifestations of written communication (Campbell, 1992).

It can be concluded from Figure 2 that the development of sophisticated innate biological schemas to communicate through facial expressions and sounds was an important

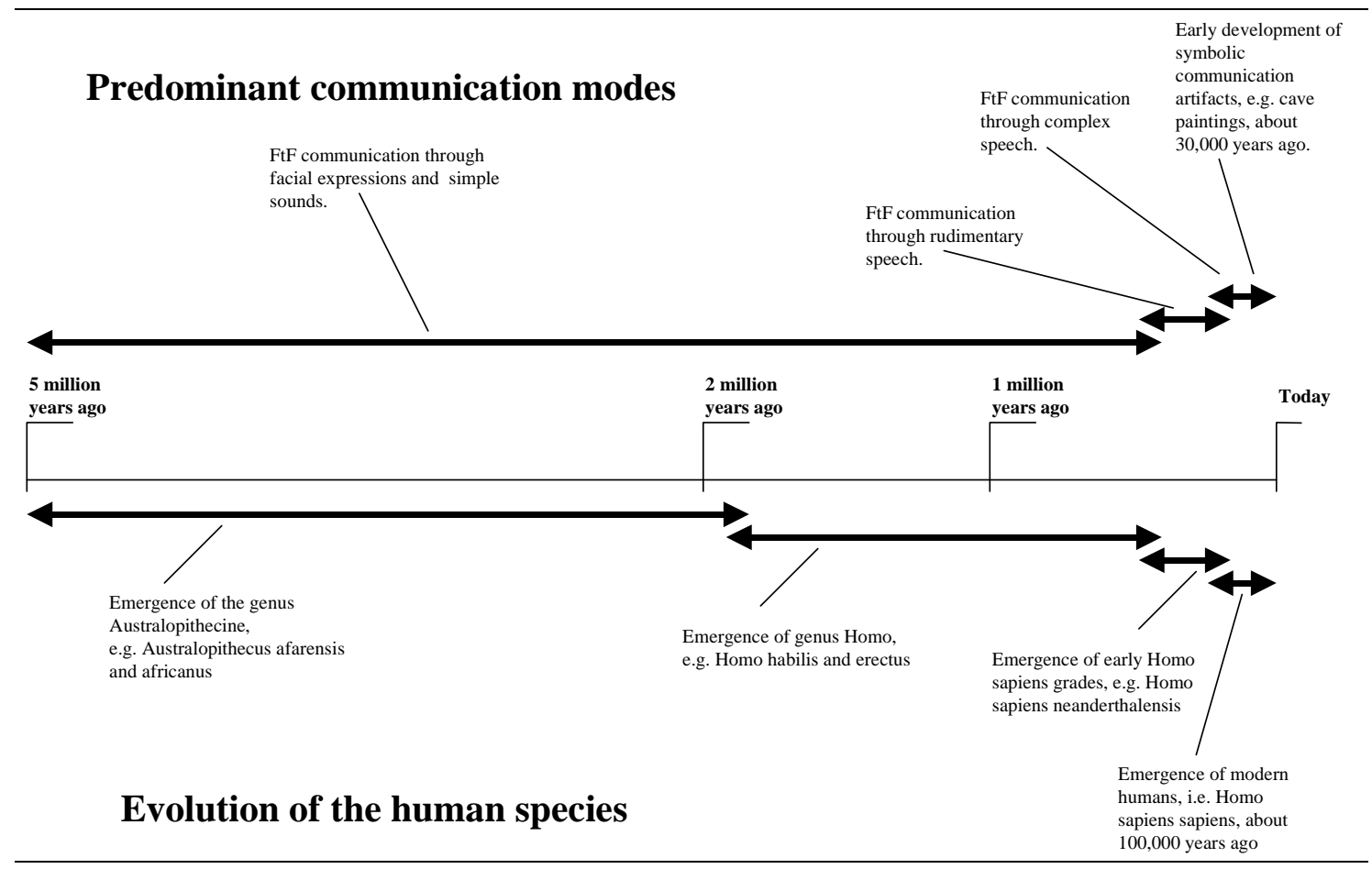

Figure 2: Communication modes at different evolutionary stages

millions of years, and are contingent on breeding speed and mortality rates). In the case of the human species, this process is not believed to have led to significant physical and cognitive changes in at least the last 30,000 years (Campbell, 1992; Dozier, 1992). During the vast majority of this process, human beings and their ancestors communicated FtF (see Figure 2). element in the evolution path that led to the human species. Such apparatus includes a complex web of facial muscles, nerves, specialized brain functions, and what Laitman (1993) believes to be a key morphological trait that differentiates human beings from their early ancestors (and modern primates). This morphological trait is a larynx lo- 


\section{Behavior Toward E-Communication Tools}

cated relatively low in the neck, which considerably increases the variety of sounds that can be generated.

Given the highly developed sense of vision already present in members of the australopithecine genus (Boaz and Almquist, 1997), it is reasonable to assume that sounds were not frequently used alone for communication (e.g., only sounds, without gestures and facial expressions). Media other than FtF interaction would require some form of sound or symbol (e.g., a pictorial representation) storage artifact. Paintings (mostly in caves) are probably the most rudimentary of such artifacts yet they appeared relatively late in the human evolutionary cycle, after complex speech is believed to have emerged. Sound storage artifacts appeared only much later, after civilization was well established. Therefore, it follows that FtF communication, with the use of discrete sounds and visual cues, has been the predominant mode of communication used by human beings over millions of years of evolution.

The absence of studies and theoretical frameworks incorporating the impact of evolutionary forces on ecommunication behavior contrasts with evidence of the strong effect that these forces have on human behavior in general (Lorenz, 1970; 1983). This is evidence of what we refer here to as the forgotten role of biology in ecommunication research, illustrated by the fact that neither technological nor social theories paid much attention to the role of innate schemas in defining behavior toward ecommunication systems.

\section{A theoretical model of biological influences}

In spite of the longstanding academic focus on technology, task and social influences, the previous evolutionary discussion suggests the important role that biology may play in influencing behavior toward technology. The perceived adequacy of communication media for a given task is likely to be at least partially moderated by their fit with the communication apparatus endowed on us by evolution. This does not deny that such perceived adequacy is also likely to be moderated by social influences. However, our goal here is to clarify the influence of biological traits on these perceptions. This is formalized in the two media adequacy propositions below.

P1: Biological traits present in the human species bias an individual's perception of a preferred communication medium toward FtF interaction for most tasks, particularly those requiring intense communication.

P2: E-communication media that incorporate elements of actual unencumbered $\mathrm{FtF}$ interaction (e.g., physical presence, ability to see and hear others, synchronicity) will be perceived as more adequate for communication than other media devoid of those elements, and therefore as demanding less individual cognitive effort to be used, particularly in tasks requiring intense communication.

The two propositions above are closely related and incorporate one of the basic hypotheses of media richness theory, which states that different communication media are perceived by users according to a richness scale (Daft and Lengel, 1986). Such richness scale features FtF interaction at the top, as the richest medium. Other media that are not as capable of conveying non-verbal cues and allowing for immediate feedback, both key capabilities of the $\mathrm{FtF}$ medium, are placed lower in the media richness scale (Daft and Lengel, 1986; Daft et al., 1987; Lengel and Daft, 1988).

Several studies succeeded in showing some of media richness theory's flaws, by providing evidence, for example, that the media richness scale is not static (Markus, 1994), and that "richness" is not inherent in a communication medium and can vary depending on who is involved in the communication act (Lee, 1994). However, the hypothesis that individuals perceive media according to a scale of richness featuring FtF interaction at the top of the scale has been more often than not supported by empirical evidence (Markus, 1994; Rice, 1992; Webster and Trevino, 1995). This hypothesis cannot be ignored and its relevance is underlined by the simple fact that perceptions affect behavior. Not only are propositions P1 and $\mathbf{P 2}$ consistent with this hypothesis, but they also provide a foundation on which to understand it. Moreover, since the propositions isolate the influence of innate from social schemas, they provide a robust theoretical foundation that is not contradictory with previous studies that showed the flaws of media richness theory (e.g., Markus, 1994 and Lee, 1994).

\section{Conclusion}

It is undeniable that, differently from less evolved animal species, much of the behavior displayed by human beings is a result of the interplay between biological and social influences. In inspecting the biological influences model's 
Ned Kock

propositions, one may argue that such interplay is not accounted for. Whether this is seen as true or not depends on how the model is interpreted. The biological influences model proposed here isolates biological from social influences and their impact on behavior. As such, it takes an analytical approach to the problem of explaining media adoption and use. Yet, it does not try to explain how the combination of innate and socially constructed schemas affects behavior. There is a fundamental reason for that. Since social influences have been demonstrated to often have a fairly unpredictable effect on behavioral aspects of technology adoption and use in socially diverse groups (DeSanctis et al., 1993), those behavioral traits induced by a combination of innate and socially constructed schemas are also likely to incorporate a certain degree of unpredictability. The biological influences model proposed here addresses this problem by isolating behavioral traits that seem to be largely due to biological influences. These, the model argues, are simpler, more predictable, and somewhat independent from social influences. In doing so, the model contributes to the predictability of social phenomena involving technology use.

Given the massive and growing deployment of information technology in organizations today and the increasing uncertainty about the effects of this technology on humans, we believe that the search for predictability in humancomputer interaction is strongly warranted. This paper is a first step in that search. The real challenge for the future, beyond expanding, validating, and refuting or refining the biological influences model proposed here, is to develop a theory that can be used to explain e-communication behavior in its full complexity. The biological influences model is not and never will be such grand theory, but we believe it can be useful in its development.

\section{References}

Alavi, M. (1994), Computer-Mediated Collaborative Learning: An Empirical Evaluation, MIS Quarterly, V.18, No.2, pp. 159-174.

Allen, D.G. and Griffeth, R.W. (1997), Vertical and Lateral Information Processing: The Effects of Gender, Employee Classification Level, and Media Richness on Communication and Work Outcomes, $\mathrm{Hu}$ man Relations, V.50, No.10, pp. 1239-1260.

Bandura, A. (1986), Social Foundations of Thought and Action, Prentice Hall, Englewood Cliffs, NJ.

Bartlett, F. (1932), Remembering: A Study in Experimental and Social Psychology, Cambridge University Press, Cambridge, MA.
Boaz, N.T. and Almquist, A.J. (1997), Biological Anthropology: A Synthetic Approach to Human Evolution, Prentice Hall, Upper Saddle River, NJ.

Campbell, B.C. (1992), Humankind Emerging, HarperCollins, New York, NY.

Carlson, P.J. and Davis, G.B. (1998), An Investigation of Media Selection Among Directors and Managers: From "Self" to "Other" Orientation, MIS Quarterly, V.22, No.3, pp. 335-362.

Daft, R.L. and Lengel, R.H. (1986), Organizational Information Requirements, Media Richness and Structural Design, Management Science, V.32, No.5, pp. 554-571.

Daft, R.L., Lengel, R.H. and Trevino, L.K. (1987), Message Equivocality, Media Selection, and Manager Performance: Implications for Information Systems, MIS Quarterly, V.11, No.3, pp. 355-366.

Darwin, C. (1859), On the Origin of Species, John Murray, London, England.

Dawkins, R. (1989), The Selfish Gene, New Edition, Oxford University Press, New York, NY.

Dennis, A.R. (1996), Information Exchange and Use in Group Decision Making: You Can Lead a Group to Information, but You Can't Make It Think, MIS Quarterly, V.20, No.4, December, pp. 433455.

Dennis, A.R. and Gallupe, R.B. (1993), A History of Group Support Systems Empirical Research: Lessons Learned and Future Directions, Group Support Systems: New Perspectives, Jessup, L.M. and Valacich, J.S. (Eds), Macmillan, New York, NY, pp. 59-77.

Dennis, A.R., Haley, B.J. and Vanderberg, R.J. (1996), A Meta-analysis of Effectiveness, Efficiency, and Participant Satisfaction in Group Support Systems Research, Proceedings of the 17th International Conference on Information Systems, DeGross, J.I., Jarvenpaa, S. and Srinivasan, A. (Eds), The Association for Computing Machinery, New York, NY, pp. 278-289.

DeSanctis, G. and Poole, M.S. (1994), Capturing the Complexity in Advanced Technology Use: Adaptive Structuration Theory, Organization Science, V.5, No.2, pp. 121-147.

DeSanctis, G., Poole, M.S., Dickson, G.W. and Jackson, B.M. (1993), Interpretive Analysis of Team Use of Group Technologies, Journal of Organizational Computing, V.3, No.1, pp. 1-29.

Dozier, R.W., Jr. (1992), Codes of Evolution, Crown Publishers, New York, NY.

Fulk, J. (1993), Social Construction of Communication Technology, Academy of Management Journal, V.36, No.5, pp. 921-938.

Fulk, J., Schmitz, J. and Steinfield, C.W. (1990), A Social Influence Model of Technology Use, Organizations and Communication Technology, Fulk, J. and Steinfield, C. (Eds), Sage, Newbury Park, CA, pp. 117-140. 


\section{Behavior Toward E-Communication Tools}

Galbraith, J. (1973), Designing Complex Organizations, AddisonWesley, Reading, MA.

Galbraith, J. (1977), Organizational Design, Addison-Wesley, Reading, MA.

Gardner, H. (1985), The Mind's New Science, Basic Books, New York, NY.

Glaser, B.G. (1992), Emergency versus Forcing: Basics of Grounded Theory Analysis, Sociology Press, Mill Valley, CA.

Gould, S.J. (1981), The Mismeasure of Man, Norton \& Company, New York, NY.

Isaac, G.L. (1993), Aspects of Human Evolution, The Human Evolution Source Book, Ciochon, R.L. and Fleagle, J.G. (Eds), Prentice Hall, Englewood Cliffs, NJ, pp. 263-273.

Jackson, M.H. and Purcell, D. (1997), Politics and Media Richness in World Wide Web Representations of the Former Yoguslavia, Geographical Review, V.87, No.2, pp. 219-239.

Kock, N. (1998), Can Communication Medium Limitations Foster Better Group Outcomes? An Action Research Study, Information \& Management, V.34, No.5, pp. 295-305.

Kock, N. (1999), Process Improvement and Organizational Learning: The Role of Collaboration Technologies, Idea Group Publishing, Hershey, PA.

Laitman, J. (1993), The Anatomy of Human Speech, The Human Evolution Source Book, Ciochon, R.L. and Fleagle, J.G. (Eds), Prentice Hall, Englewood Cliffs, NJ, pp. 56-60.

Lee, A.S. (1994), Electronic Mail as a Medium for Rich Communication: An Empirical Investigation Using Hermeneutic Interpretation, MIS Quarterly, V.18, No.2, pp. 143-157.

Lengel, R.H. and Daft, R.L. (1988), The Selection of Communication Media as an Executive Skill, Academy of Management Executive, V.2, No.3, pp. 225-232.

Lorenz, K. (1970), Studies in Animal and Human Behavior, Harvard University Press, Cambridge, MA.

Lorenz, K. (1983), The Waning of Humaneness, Little, Brown \& Co, Boston, MA.

Markus, M.L. (1990), Toward a Critical Mass Theory of Interactive Media, Organizations and Communication Technology, Fulk, J. and Steinfield, C. (Eds), Sage, Newbury Park, CA, pp. 194-218.

Markus, M.L. (1992), Asynchronous Technologies in Small Face-toFace Groups, Information Technology \& People, V.6, No.1, pp. 29-48.

Markus, M.L. (1994), Electronic Mail as the Medium of Managerial Choice, Organization Science, V.5, No.4, pp. 502-527.
Markus, M.L. and Robey, D. (1988), Information Technology and Organizational Change: Causal Structure in Theory and Research, Management Science, V.34, No.5, pp. 583-598.

Ngwenyama, O.K. and Lee, A.S. (1997), Communication Richness in Electronic Mail: Critical Social Theory and the Contextuality of Meaning, MIS Quarterly, V.21, No.2, pp. 145-167.

Nunamaker, J.F., A.R. Dennis, J.S. Valacich, D.R. Vogel, J.F. George (1991), Electronic Meeting Systems to Support Group Work, Communications of ACM, V.34, No.7, pp. 40-61.

Orlikowski, W.J. and Yates, J. (1994), Genre Repertoire: The Structuring of Communicative Practices in Organizations, Administrative Science Quarterly, V.39, No.4, pp. 541-574.

Orlikowski, W.J., Yates, J., Okamura, K. and Fujimoto, M. (1995), Shaping Electronic Communication: The Metastructuring of Technology in the Context of Use, Organization Science, V.6, No.4, pp. 423-444.

Pal, B. (1999), Email Contact Between Doctor and Patient, British Medical Journal, V.318, No.7195, p. 1428.

Poole, M.S. and DeSanctis, G. (1990), Understanding the Use of Group Decision Support Systems: The Theory of Adaptive Structuration, Organizations and Communication Technology, Fulk, J. and Steinfield, C. (Eds), Sage, Newbury Park, CA, pp. 173-193.

Postmes, T., Spears, R. and Lea, M. (1998), Breaching or Building Social Boundaries? Side-effects of Computer-mediated Communications, Communication Research, V.25, No.6, pp. 689715 .

Rice, R.E. (1992), Task Analyzability, Use of New Media, and Effectiveness: A Multi-Site Exploration of Media Richness, Organization Science, V.3, No.4, pp. 475-500.

Rice, R.E and Shook, D.E. (1990), Relationship of Job Categories and Organizational Levels to Use of Communication Channels, Including Electronic Mail: A Meta-Analysis and Extension, Journal of Management Studies, V.27, No.2, pp. 195-230.

Sproull, L. and Kiesler, S. (1991), Computers, Networks and Work, Scientific American, V.265, No.3, pp. 84-91.

Strauss, A. and Corbin, J. (1990), Basics of Qualitative Research: Grounded Theory Procedures and Techniques, Sage, Newbury Park, CA.

Webster, J. and Trevino, L.K. (1995), Rational and Social Theories as Complementary Explanations of Communication Media Choices: Two Policy-Capturing Studies, Academy of Management Journal, V.38, No.6, pp. 1544-1573.

Whitfield, J. and Lamont, M. (1996), The Effects of Organization Design on Media Richness in Multinational Enterprises, Management Communication Quarterly, V.10, No.2, pp. 209-237. 
Yates, J. and Orlikowski, W.J. (1992), Genres of Organizational Communication: A Structurational Approach to Studying Communication and Media, Academy of Management Review, V.17, No.2, pp. 299-326.

Zigurs, I. and Buckland, B.K. (1998), A Theory of Task/Technology Fit and Group Support Systems Effectiveness, MIS Quarterly, V.22, No.3, pp. 313-334.

\section{Acknowledgements}

The study reported here has been funded in part by Temple University, and by a grant from the US Department of Defense.

\section{Biographies}

Ned Kock is a CIGNA Research Fellow in the Fox School of Business and Management, and professor of information systems in the departments of Management Information Systems and Computer and Information Sciences, Temple University. He holds a PhD in information systems from the University of Waikato, New Zealand. He is the author of three books, including Process Improvement and Organizational Learning: The Role of Collaboration Technologies (Idea Group Publishing), and several articles in journals such as Communications of the ACM, Journal of Organizational Computing and Electronic Commerce, Information \& Management, Information Systems Journal, and Information Technology \& People. Ned is co-editor of the ISWorld Professional Ethics Section, associate editor of the Journal of Systems and Information Technology, and member of the editorial board of the Journal of Information Technology Cases and Applications. 